\title{
Information Modeling for Thermal Fatigue Evaluation of Power Plant Pipelines
}

\author{
Te-Wei Fan ${ }^{1, *}$,Chao-Jen $\mathrm{Li}^{2}$ and Ming-Sung Huang ${ }^{3}$ \\ ${ }^{1,3}$ Department of Civil Engineering, Chung Hua University, No. 707, Sec. 2, Wufu Rd., Xiangshan District, Hsinchu City, \\ Taiwan \\ ${ }^{2}$ Material and Chemical Research Labs, Industrial Technology Research Institute, Rm.637, Bldg.52, 195, Sec.4, Chung Hsing \\ Rd., Chutung, Hsinchu, 31040, Taiwan, R.O.C. \\ ${ }^{*}$ Corresponding author
}

\begin{abstract}
Thermal fatigue and cracking of un-isolable pipelines caused by mixing of cold and hot water in pipelines have been reported. This is because the builder's system designs are all based on foreign technology, and assessments are needed to prevent similar thermal fatigue problems from occurring to power plant pipelines in Taiwan.

There have been numerous pipeline valve leak examples in similar foreign power plants. Consequently, the Electric Power Research Institute (EPRI) has proposed special assessments for cold and hot water mixing in un-isolable pipelines. The technical report issued by EPRI focuses on the thermal fatigue safety assessment of unisolable pipeline and $\mathrm{T}$-shape pipelines in power plants. This assessment not only can determine the thermal fatigue status in pipelines and the appropriate detection cycle, but can also provide a corresponding pipeline safety assessment solution during application of power plant extension of service.

Entry pipe geometric conditions, temperature, pressure, and flow rate were inputted to calculate whether pipeline temperature difference and temperature history that can cause thermal fatigue exists. Subsequently, fatigue factor calculation was conducted on pipeline that may have thermal fatigue. Power plant personnel's actual operating experiences were also surveyed in this study to supplement data that drawings cannot provide. Design parameters and actual operating parameters were compared as an assessment basis for future power plant operations.

In response to the new building information modeling (BIM) technology, we applied its database characteristics to build a pipeline model for pipes within the focus scope. This can achieve visualization management function. Furthermore, the building of the pipeline model database can give users mastery over pipeline design and current status, and can avoid the need to search through large amount of drawing data. Linking the model with the calculation formula can give more comprehensive added value to the database. Digital network can be used to share model information with the possessors of different projects, thereby, promote synchronization of information sharing and information delivery.
\end{abstract}

Keywords- information modeling; thermal fatigue; piping

\section{INTRODUCTION}

In recent years, news of thermal fatigue and cracking of unisolable pipelines have been reported. Although there is no example of similar leaks in Taiwan, preventive system assessments must be conducted to prevent similar incidents from occurring in domestic systems.
Electric Power Research Institute (EPRI) indicated that thermal fatigue can occur in some pipeline with level stagnant water, and that cold/hot mix can occur in T-shaped pipelines. Because of these aforementioned reasons, the American Nuclear Regulatory Commission (NRC) has proposed that power plants need to propose pipeline fatigue and aging management solutions if they are to apply for extension of service. After many years of use Taiwan power plants are also facing extension of service issues. These power plants must repair fatigued and aging pipelines, and prevent leaks (as a result of use time, cold/hot mix) from occurring like examples given in the BWRVIP-155[1] and BWRVIP-196[2] technical reports.

In addition, the database characteristics of the new BIM technology can be used to build a pipeline model with the appropriate scope to achieve visualization and management functions. The answer to whether building information modeling (BIM) is needed can be found in IT's Communication [3]. Traditionally, design and construction have been independently and professionally implemented. However, problems can occur when different professions overlap. For example, when there is a design conflict or the design becomes more complex, the lack of a two-way correlation between drawings can cause missed items or incomplete repair/revisions. BIM can simulate possible situations such as budget, work time, conflicts, and follow-up operation and maintenance on the computer.

\section{LITERATURE REVIEW}

There are many international examples of thermal fatigue related cracking in pipelines. Overall, a total of 14 examples exist in American, Japanese, French, and Belgium power plants. Subsequently, the EPRI proposed a thermal fatigue assessment technical report (BWRVIP-155) in June 2006. The election assessment in this report pointed out that pipeline level stagnant water in un-isolable pipeline can cause thermal fatigue in BWR3, BWR-4, and BWR-6 type boiling water reactor (BWR) power plants. The main cause for this is the incomplete separation of the separation valve, which allows cold and hot water to mix and produce laminar flow. Pipeline cannot bear the long-term alternating stress produced by the cold and hot alternation and cracks or become brittle to the point of breaking. RHR system pipeline rupture examples can be found in French and Japanese power plants. The main cause of these ruptures is hot and cold water mixing in T-Shaped pipeline connectors, which produce thermal fatigue and cracking. 
Two years after EPRI issued BWRVIP-155, EPRI issued the BWRVIP-196, which is a technical report that focuses on thermal fatigue caused by cold/hot mix in T-shaped pipelines in BWR power plants. This report indicated that when there is a cold/hot mix situation in the T-pipe location where reactor water cleaning unit (RWCU) returns to the feedwater (water injection system), there may be a concern of thermal fatigue. Because of these leak reasons, the American Nuclear Regulatory Commission (NRC) proposed that power plants must provide relevant pipeline fatigue and aging management solutions when they apply for extension of service. NRC also indicated that power plants with approved license must improve detection and analysis. Thus, assessment focus should be on water injection system, non-separated pipe sections, and the pressure adjustment tank pipelines in pressurized water nuclear power plants [4].

\section{OBHECTIVE AND SCOPE}

Although power plant initial construction has already considered fatigue problems, there are still potential compound problems such as thermal fatigue, thermal flow, materials, and power plant actual operations. Traditional monitoring and testing cannot solve power plant problems. Researcher in this study hope to use application of relevant technical specifications to implement an assessment model designated to un-isolable pipelines and T-pipe cold/hot mix. Furthermore, BIM database link and management function was added to existing power plant operation to increase convenience of accessing drawing database Visualization method is used to build a pipeline model so users can immediately search and read drawings in the database.

The following are the objectives of this study:

1. Selection and assessment/analysis of un-isolable pipelines with thermal fatigue.

2. Selection and assessment/analysis of cold/hot mix Tshape pipelines.

3. Building of pipeline visualization and database.

Relevant technical reports issued by the EPRI were used as assessment basis in this study to conduct the following work:

4. BWRVIP-155 is primarily focused on un-isolable pipelines, and uses reactor connection to the water circulation system and water injection system as the research scope.

5. MRP-146S is primarily focused on the assessment of DH model pipelines in un-isolable pipelines.

6. BWRVIP-196 is primarily focused on T-shaped pipeline cold/hot mix. This report inspects T-shaped pipeline with cold/hot mix, including pipelines in the residual heat removal system, reactor water cleaning unit, high pressure water injection system, low pressure water injection system, reactor core isolation cooling system, and the reactor core spray system.

7. Use of MRP-170 Excel analysis program to conduct assessment.

\section{AsSESSMENT OF Thermal FAtigue}

This paper is focused on BWR type power plants and the possible hot/cold cycle thermal fatigue problem in their pipelines. The main scope of this study is the branch pipes that are connected to the reactor water circulation system and water injection system. The water circulation system has two main functions. The first is to provide forced cooling water to the reactor core so the reactor core can produce higher power output. The second function is to adjust and change the flow that enters the reactor core, thereby, adjusting the reactor's power [5-18].

\section{A. Description of Analysis Conditions}

Assume that the environment temperature is $100^{\circ} \mathrm{F}\left(38^{\circ} \mathrm{C}\right)$ during DH pipeline assessment work. The heat insulation material thickness that covers pipelines during $\mathrm{DH}$ pipeline assessment work was obtained from the power plant's Piping List. Heat insulation material's thermal conductivity was set at $0.036 \mathrm{BTU} / \mathrm{hr}-\mathrm{ft}-{ }^{\circ} \mathrm{F}$. Although this assumed heat insulation material thermal conductivity parameter may be different from actual situation, but experience shows that the effects of this parameter do not exceed $20^{\circ} \mathrm{F}\left(10^{\circ} \mathrm{C}\right)$.

We used power plant Unit 1/Unit 2 pipelines (12"-FW$22 \mathrm{~S} / 72 \mathrm{~S}$ ) as an example. When the MRP-170 program showed concerns for incomplete separation, pipeline stress and accumulated use fatigue factor assessment were then conducted for the pipelines in question. The MRP-146S described further assessment and tools for DH type branch pipes. In this chapter, we specifically described the procedure for conducting pipeline stress assessment and accumulated use fatigue factor calculation.

Each cycling period has been labeled with the maximum alternating stress. Of which, the red-highlights indicates the location of the highest alternating stress, None of the alternating stress in the aforementioned table exceeds $80 \mathrm{ksi}$. Thus, ASMEcode Fatigue Curve 5-110.1 was used to conduct accumulated use fatigue factor calculation.

\section{B. Assessment results}

These pipelines have been operating for 40 years and 60 years, which means that the pipeline accumulated use fatigue factor will be greater than 1 . Therefore, the power plant shall conduct detection for every overhaul. The above assessed DH pipeline was assessed based on MRP-146S procedures. The material in this example was carbon steel and the non-technical example was stainless steel. However, because there are no carbon steel technical specifications or assessment methods, we used specifications first. If carbon steel technical specifications become available later, appropriate changes shall be made. We would like to specially note that point here. was stainless steel. However, because there are no carbon steel technical specifications or assessment methods, we used specifications first. If carbon steel technical specifications become available later, appropriate changes shall be made. We would like to specially note that point here.

To cite ITRI's organization on T-shaped pipeline thermal fatigue [4], thermal fatigue damage caused by hot/cold water mixing often occurs in the mixing tee and after the downstream pipeline weld. The affected length is limited to three times the diameter. The temperature difference at the pipe wall is used as the selection indicator: Rules are as follows: 
For stainless steel pipelines, no assessment is needed if the post-mixture temperature difference $(\Delta \mathrm{T})$ is less than $144^{\circ} \mathrm{F}$ $\left(80^{\circ} \mathrm{C}\right)$. For carbon steel pipelines, no assessment is needed if its post-mixture temperature difference $(\Delta \mathrm{T})$ is less than $90^{\circ} \mathrm{F}$ $\left(50^{\circ} \mathrm{C}\right)$. The selection condition for this indicator assumes that the pipe wall fluid temperature difference is $80 \%$. Assessment is required for pipe wall temperature difference that exceeds the aforementioned temperature limitation.

We conducted assessments for six major systems. However, the power plant does not have a reactor core spray system. Therefore, we first assessed T-shaped pipeline positions with possible cold/hot mix fatigue for the five systems with drawings. Monitoring system was set up for the selected positions in the power plant to obtain actual measurement data. One of the ISO diagram which indicating hot and cold water mixing T-junction was looked up and shown as figure I.

\section{Calculation of Valid T-Shaped Pipeline Time with Actual Operation Parameters}

MRP-192 can be used to reference the valid time, which can then be used to calculate the valid hours and life in actual operations. Using the stainless steel in the technical report as an example, the equation is $(\Delta T / 270) 2.2$. However, because this example is carbon steel material, the crack growth equation should be revised into $(\Delta \mathrm{T} / 220) 5.95$. Based on the ISO diagram to locate the monitoring position and operating temperature history was recorded for $6 \mathrm{~K}-6 \mathrm{AN}$ outlet of heat exchanger. It was derived that the maximum temperature difference is $163^{\circ}$ $\mathrm{F}$, and the effective operating time is 0.002 hours with corresponding 346153.8 operating years.

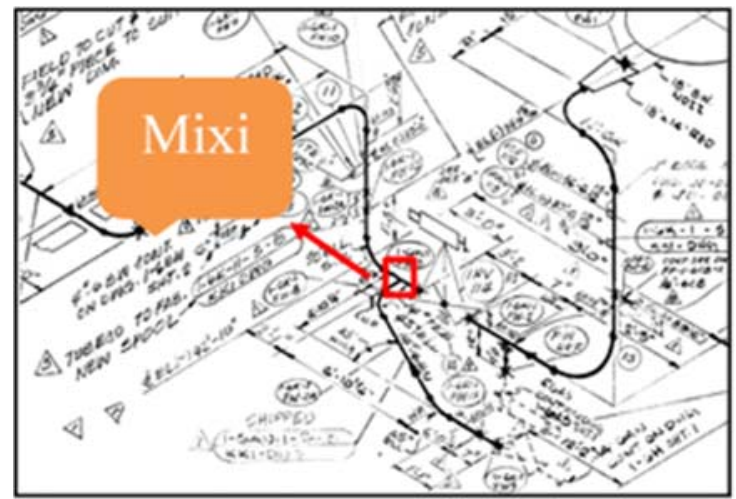

FIGURE I. ISO DIAGRAM OF HOT-COLD WATER MIXED-T JUNCTION PIPLINES

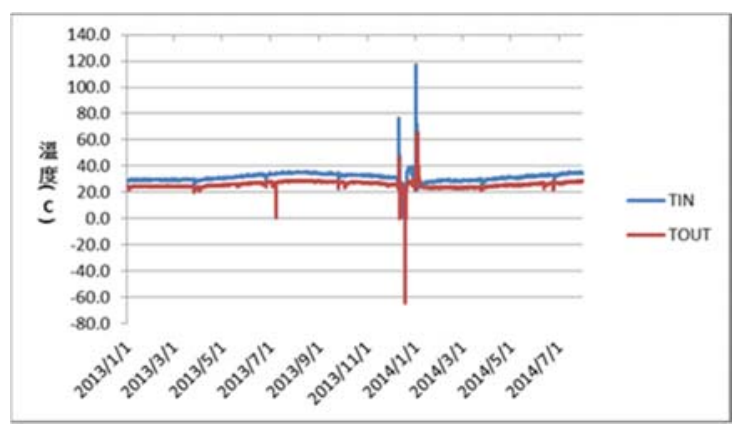

FIGURE II. TEMPERATURE HISTORY OF 6K-6AN OUTLET OF HEAT EXCHANGER

\section{Building of Pipeline Model Data}

After the selection and assessment of T-pipes, we built the pipeline data model and saved the pipeline drawings to facilitate search. The software tool used was REVIT 2016 and the P\&ID diagram imported is as shown in figure III. The constructed model scope includes pipelines from the water injection pipeline to the reactor as shown in figure IV, and the data display is as shown in figure $\mathrm{V}$, The pipeline diameter, length, and elevation were all built into the model. The model was linked to analysis program MRP-170 to make its database complete as shown in figure VI.

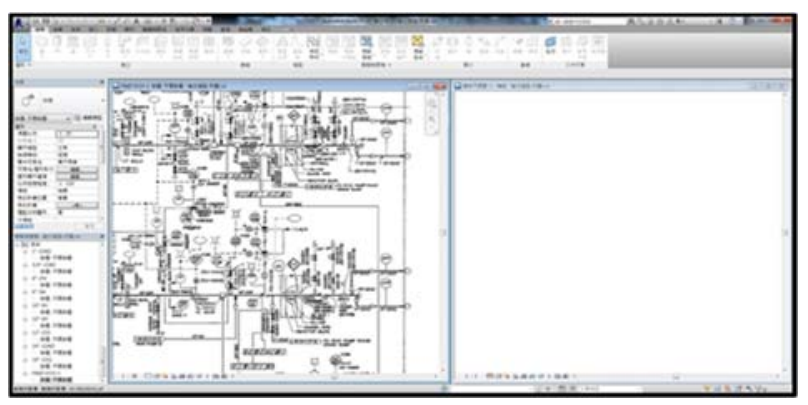

FIGURE III. P\&ID DIAGRAM IMPORTED IN REVIT

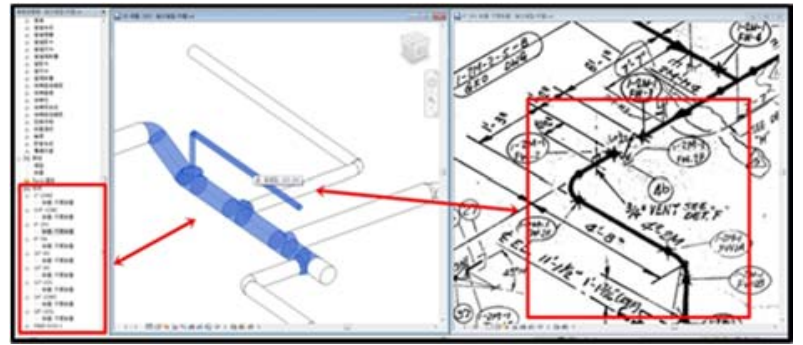

FIGURE IV. 3D WATER INJECTION PIPELINE MODEL

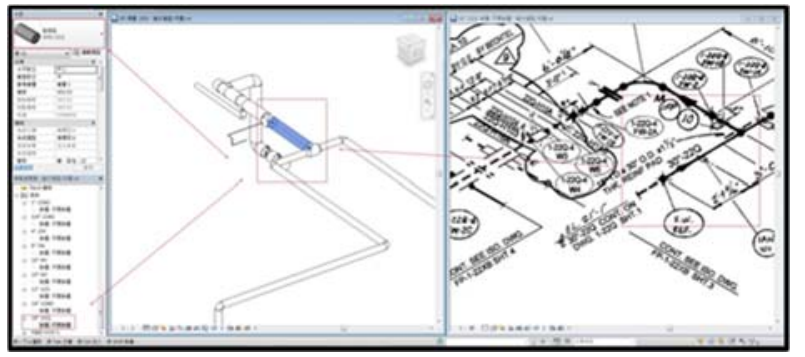

FIGURE V. DATABASE DISPLAY FOR WATER INJECTION PIPELINE MODEL

\section{SUMMARY}

In this study, selection standards from multiple technical report issued by the EPRI was used to select un-solable pipelines and T-shaped pipeline with possible thermal fatigue. A BIM pipeline database model was used to integrate drawings with pipelines. The following is the conclusion obtained by this study, with the corresponding clarifications.

Thermal fatigue assessment results for un-isolable pipelines: power plant Unit 1 and 2 each has 11 pipelines that had been screen in. A total of 18 pipelines have the potential thermal fatigue problems. Of which, $\mathrm{H} / \mathrm{UH}$ model pipelines that have 
been screened in include 10"-RHR-6V/56V, 10"-RHR-6X-56X, 10"-FW-22AQ/72AQ, 10"-FW-22AR-/72AR, 10"'-FW22AS/72AS, 12"-FW-22AH/72AH, and 12"-FW-22M/72M. DH model pipelines that have been screened in include 6"RCIC-5A/55A and 12"-FW-22S/72S.

According to MRP-146, because H/UH pipelines selected from un-isolable pipelines do not have a fatigue accumulation factor assessment procedure, they must be tested during every major power plant maintenance. Testing frequency for $\mathrm{DH}$ pipelines shall be set based on the values/results of their accumulated use fatigue factor calculation. In addition, the operating flow rate parameter was deleted by the MRP-170 program when determining pipelines. To continue the assessment process with the MRP-170 program, we removed program limitations to enable this pipeline study to proceed.

T-shaped pipeline thermal fatigue is based on MRP-196 standards. Actual assessment of power plant systems with concerns includes residual heat removal system, RWCU, and the reactor core isolation cooling system. Based on operating experience, other remaining system do not have cold/hot mix situation. According to actual power plant operating experience, original monitor point in the aforementioned system cold/hot mix T-shaped pipelines loses the original pipeline fluid temperature value when different temperature fluids mix. Therefore, we also recommend the most appropriate monitor points for the aforementioned systems. The location suggested for temperature monitoring which was derived from the information model calculation is as shown in figure VII for example.

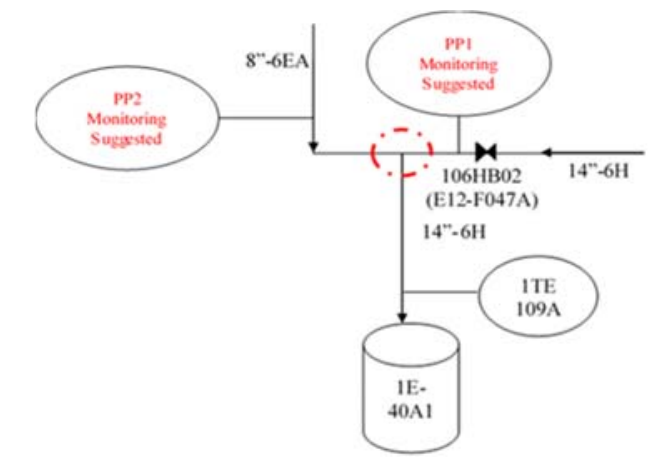

FIGURE VI. LOCATION SUGGESTED FOR TEMPERATURE MONITORING DERIVED FROM CALCULATION OF THE INFORMATION MODELING

The valid time calculation in $\mathrm{T}$-shaped pipeline actual operating value and calculation result for RHR heat exchanger entry/exit and RWCU return to water injection pipeline both conform to existing data collection conclusions for the system published in the technical report. Although the life of the RWCU return to water injection pipe is shorter, thermal sleeves have been installed in that location during the construction of the plant, and the actual thermal fatigue situation should be less severe than the assessment results.

Building a BIM pipeline model and combining it with a drawing database can closely describe pipeline model and help related personnel decrease drawing search time. The pipeline model can also be placed on a network platform so the project owner can search for model information with different carriers

\section{REFERENCES}

[1] EPRI, "Evaluation of Thermal Fatigue Susceptibility in BWR Stagnant Branch Lines (BWRVIP-155),"Final Report, California, U.S.A. (2006).

[2] EPRI, "Assessment of Mixing Tee Thermal Fatigue Susceptibility in BWR Plants (BWVIP196)," Final Report, California, U.S.A. (2008).

[3] Hsu Wen-Kuo (2011), "IT'S Communication"

[4] Li Chao-Jen et al., Thermal Fatigue Safety Assessment and Management for Un-isolable Pipelines and T-Shaped Pipelines in Boiling Water Nuclear Power Plants; interim report, Taiwan Power Company, Hsinchu (2012).

[5] Taiwan Power Company, Nuclear Power Plant 2 training material Chapter 16 Condensation Water and Feed Water System.

[6] Li Chao-Jen et al., Safety Assessment and Management of Thermal Fatigue in Un-isolable Pipelines in Pressurized Water Nuclear Power Plants, completion report, Taiwan Power Company, Hsinchu (2012).

[7] EPRI, "Assessment of Residual Heat Removal Mixing Tee Thermal Fatigue in PWR Plants (MRP-192, Revision 2)," Final Report, California, U.S.A. (2012).

[8] EPRI, "Management of Thermal Fatigue in Normally Stagnant NonIsolatable Reactor Coolant System Branch Lines (MRP-146, Revision 1)," Final Report, California, U.S.A. (2011).

[9] EPRI, "Thermal Fatigue Monitoring Guidelines (MRP-32, Revision 1)," Final Report, California, U.S.A. (2011).

[10] EPRI, "Management of Thermal Fatigue in Normally Stagnant NonIsolable Reactor Coolant System Branch Lines-Supplemental Guidance (BWRVIP-155)," Final Report, California, U.S.A. (2009).

[11] EPRI, "Management of Thermal Fatigue in Normally Stagnant NonIsolable Reactor Coolant System Branch Lines (MRP-146)," Final Report, California, U.S.A. (2005).

[12] EPRI, "Thermal Cycling Screening and Evaluation Model for Normally Stagnant Non-Isolatable Reactor Coolant Branch Line Piping with a Generic Application Assessment (MRP-132),” Final Report, California, U.S.A. (2004)

[13] EPRI, "EPRI Thermal Fatigue Evaluation per MRP-146 (MRP-170)," Final Report, California, U.S.A. (2003).

[14] EPRI, "Operating Experience Regarding Thermal Fatigue of NonIsolatable Piping Connected to PWR Reactor Coolant Systems (MRP-25)," Final Report, California, U.S.A. (2000).

[15] Masayuki Kamaya, Akira Nakamura, "Thermal stress analysis for fatigue damage evaluation at a mixing tee," Journal of Nuclear Engineering and Design, Science Direct, Vol. 241, pp. 2674-2687 (2011).

[16] Jungjun Park et al., "3D/4D CAD Applicability for Life-Cycle Facility Management," Journal of Computing of Civil Engineers, ASCE, Vol. 25, No. 2, pp.129-138 (2011).

[17] K.-J. Metzner, U. Wilke, "European THERFAT project-thermal fatigue evaluation of piping system Tee-connections," Journal of Nuclear Engineering and Design, ScienceDirect, VOl. 235, pp. 473-484 (2005).

[18] S. Chapuliot et al., Hydro-thermal-mechanical analysis of thermal fatigue in a mixing tee, Journal of Nuclear Engineering and Design, Science Direct, Vol. 235, pp. 575-596(2005). 